\title{
Selection of Patients with Stroke for Thrombectomy Must Be Judicious and Should Not Be Offered to Any Patient with Large-Vessel Occlusion with a Femoral Pulse
}

I $\mathrm{n}$ this issue of the American Journal of Neuroradiology (AJNR), the authors reported their findings in the retrospective study, "Clinical Outcome after Thrombectomy in Patients with Stroke with Premorbid Modified Rankin Scale Scores of 3 and 4: A Cohort Study with 136 Patients." ${ }^{1}$ The authors examined outcomes of patients with notable premorbid impaired functional status who underwent endovascular thrombectomy for the treatment of acute ischemic stroke. The bottom line was that approximately $20 \%$ of patients returned to their baseline premorbid function, and the authors concluded that endovascular thrombectomy could be justified in this group of patients.

The authors' conclusion represented a notable departure from current guidelines, which were derived from the successful randomized controlled thrombectomy studies dating from 2015, culminating in 2 further successful trials extending the time window for intervention up to 24 hours after stroke onset. ${ }^{2}$ To briefly recapitulate, the American Stroke Association guidelines stipulated that the group of patients most likely to benefit was those with premorbid modified Rankin Scale scores of $0-2$. The downstream effect of the guidelines was that those patients with notable pre-morbid impairment mRS of 3 to 5 (excluding those with mRS 6 which equated death) were essentially excluded from thrombectomy. This generated debate in some quarters whether the strict adherence of guidelines "denied" treatment to a subgroup of patients who might have benefitted from treatment.

It is important to reflect on the classification of patients into different groups of the mRS. mRS 3 describes a patient with moderate disability and specifically "requiring some help but able to walk without assistance," and mRS 4 describes moderate-to-severe disability with the patient "unable to walk without assistance and unable to attend to own bodily needs without assistance." 3 The assessment of patients according to the mRS does allow room for flexible interpretation, but a patient with mRS 4 is essentially an individual who requires 24 -hour supervision and is likely to reside in a high-level-care environment.

The philosophical question of treatment should also take into account the wishes of the patients, who, with premorbid function of mRS 3 or 4, will differ substantially from those with premorbid functional independence. Pearlman et $\mathrm{al}^{4}$ in a study involving 342 patients with a mixture of stroke survivors and nursing home residents examined this salient question and found that those with notable premorbid impairment viewed their health function as "states worse than death" and clearly voiced strong reluctance to undergoing life-prolonging treatment. ${ }^{4}$ These findings are sobering in that perhaps as clinicians we have frequently adopted, sometimes justifiably in emergency situations, patriarchal standpoints and have not adequately taken into account the reluctance of patients for invasive treatment.

I commend the authors of the study in this issue of the AJNR for their investigation of thrombectomy outcomes in a group of patients with notable premorbid dysfunction. However, the results do not support a motion to alter current clinical guidelines, and I believe that the triage of patients with stroke for thrombectomy must remain judicious and that we should avoid falling into the trap of treating any patient with large-artery occlusion and a femoral pulse.

\section{REFERENCES}

1. Seker F, Pfaff J, Schönenberger S, et al. Clinical outcome after thrombectomy in patients with stroke with premorbid modified Rankin Scale scores of 3 and 4: a cohort study with 136 patients. AJNR Am J Neuroradiol 2018; CrossRef

2. Powers WJ, Rabinstein AA, Ackerson T, et al; American Heart Association Stroke Council. 2018 guidelines for the early management of patients with acute ischemic stroke: a guideline for healthcare professionals from the American Heart Association/American Stroke Association. Stroke 2018;49: e46-110 CrossRef Medline

3. Quinn TJ, Dawson J, Walters M. Dr John Rankin; his life, legacy, and the 50th anniversary of the Rankin Stroke Scale. Scott Med J 2008;53: 44-47 CrossRef Medline

4. Pearlman RA, Cain KC, Starks H, et al. Preferences for life-sustaining treatments in advance care planning and surrogate decision making. J Palliat Med 2000;3:37-48 CrossRef Medline

(D). Yan

Comprehensive Stroke Center Royal Melbourne Hospital

Parkville, Melbourne, Victoria, Australia

http://dx.doi.org/10.3174/ajnr.A5928 